Original Article

\title{
Forced respiration during the deeper water immersion causes the greater inspiratory muscle fatigue in healthy young men
}

\author{
Yoshiniro Yamashina, PT, MS ${ }^{1)}$, Hisayo Yokoyama, MD, PhD ${ }^{1 *}$, Nooshin Naghavi, $\mathrm{MS}^{1)}$, \\ Yoshikazu Hirasawa, PT ${ }^{1)}$, Ryosuke Takeda, MS ${ }^{1)}$, Akemi Ota, MS ${ }^{1)}$, Daiki Imai, PhD ${ }^{1)}$, \\ Toshiaki Miyagawa, $\mathrm{PhD}^{1)}$, Kazunobu OKazaki, $\mathrm{PhD}^{1)}$ \\ 1) Environmental Physiology for Exercise, Osaka City University Graduate School of Medicine: \\ 3-3-138 Sugimoto, Sumiyoshi-ku, Osaka 558-8585, Japan
}

\begin{abstract}
Purpose] The purpose of the present study was to evaluate the effect of water immersion at different water depths on respiratory function and the effect of inspiratory load breathing (ILB) during water immersion at different water depths on respiratory muscle strength evaluated by maximum inspiratory and expiratory pressures (PImax and PEmax, respectively). [Subjects] Eight healthy men participated randomly in three trials. [Methods] All sessions were conducted with the participants in a sitting position immersed in a water bath. We evaluated respiratory function, PImax and PEmax during submersion at three different levels of water depth (umbilicus; 4th-rib; or clavicle, CL) and after subsequent 15-min ILB. [Results] Decreases in vital capacity and expiratory reserve volume from baseline by water immersion were significantly greater in the CL trial than those in the other trials. In the CL trial, PImax was immediately reduced after ILB compared to that at baseline, and the reduction was significantly greater than those in the other trials. PEmax was not affected by ILB in any of the trials. [Conclusion] Forced respiration during deeper water immersion caused greater inspiratory muscle fatigue in healthy young men. Key words: Aquatic exercise, Respiratory muscle strength, Inspiratory load breathing
\end{abstract}

(This article was submitted Sep. 14, 2015, and was accepted Oct. 30, 2015)

\section{INTRODUCTION}

Muscle fatigue involved in inspiration, such as diaphragm muscle, external intercostal muscle, or parasternal intercostal muscle, induces a shortness of breath resulting in impaired exercise tolerance ${ }^{1,2}$. This intensity in exercising vigorously brings about consequent low physical activity. In addition, diminished respiratory muscle strength results in the reduced efficiency of coughing to remove airway secretions (phlegm), which increases the risk of atelectasis or pneumonia after surgery or prolonged bed rest ${ }^{3,4)}$.

Age-related physiological changes in the respiratory system, such as decrease in pulmonary elasticity, fusion of the sternal bone and costal cartilage, or increases in thoracic kyphosis, augment the reduction of respiratory muscle strength and respiratory function ${ }^{5}$. Indeed, in Japan, pneumonia has recently overtaken cerebrovascular disease as the third leading cause of death, reflecting the aging of society. Thus, it is essential to maintain respiratory function, including respiratory muscle strength, for a healthy daily life, particularly for the elderly.

As a part of health promotion activities, aquatic exercise has generally been accepted in the clinical settings of rehabilitation and various sports facilities ${ }^{6,7)}$. People with obesity ${ }^{8)}$, joint diseases ${ }^{9)}$, or lumbago ${ }^{10,11)}$ benefit from aquatic exercise, wherein they can avoid unnecessary exercise load on the joints because of self-weight using buoyancy and can perform exercise more safely. In addition, they can efficiently strengthen the muscles of the upper and lower extremities using water

\footnotetext{
*Corresponding author. Hisayo Yokoyama (E-mail: yokoyama@sports.osaka-cu.ac.jp)

(C)2016 The Society of Physical Therapy Science. Published by IPEC Inc.

This is an open-access article distributed under the terms of the Creative Commons Attribution Non-Commercial No Derivatives (by-nc-nd) License $<$ http://creativecommons.org/licenses/by-nc-nd/4.0/>.
} 
viscosity and pressure in aquatic exercise $\mathrm{e}^{9-12)}$.

Breathing underwater requires great effort mainly because of the following two aspects: first, blood volume shifts into the chest cavity because of the increased venous return from the lower extremities; second, inflexibility of the chest wall and diaphragm shifts toward the cranial side because of the hydrostatic pressure resulting into restricted pulmonary compliance $^{13-15)}$. Regarding the effect of water depth on respiratory function, the pulmonary vital capacity (VC), forced expiratory volume during the first second (FEV1.0), and functional residual capacity (FRC) are decreased during water immersion at the clavicular or cervical level ${ }^{16-18)}$. Furthermore, de Andrade et al. reported that the decrease in the maximum inspiratory muscle strength during water immersion was greater when the water level was at the clavicle than at the xiphoid process because of the higher water pressure at the clavicular level ${ }^{19)}$. Therefore, aquatic exercise, such as swimming or walking in water, is an ideal exercise for health promotion, which can add an aspect of resistance training through water viscosity to aerobic exercise. In addition, the specific circumstance of resistance to chest expansion during the inspiratory phase may be useful for developing respiratory muscle strength. Previous studies have reported that exercise in water for 8-10 weeks improves the respiratory muscle strength and exercise tolerance of healthy individuals, and patients with chronic obstructive pulmonary disease and spinal cord injury ${ }^{20-22}$. However, it has not been clarified how the water depth during exercise in water affects respiratory muscle strength.

Accordingly, the hypothesis was built that inspiratory muscle strength would decrease after aquatic exercise training by muscle fatigue depending on the water depth. Thus, we investigated, 1) the effect of water immersion at different water depths on respiratory function, and 2) the effect of inspiratory muscle training during water immersion at different water levels on respiratory muscle strength.

\section{SUBJECTS AND METHODS}

Sedentary, healthy male college students aged between 20 and 22 were recruited for this study. Subjects who had a history of respiratory or cardiovascular disease, hypertension (resting systolic blood pressure (BP) $\geq 140$ and/or diastolic BP $\geq 90$ ), diabetes, obesity (body mass index $(\mathrm{BMI}) \geq 30$ ), or smoking habits were excluded. The applicants who met the inclusion criteria participated in the study after familiarizing themselves with the experimental protocol, e.g. the spirometry measurement method and inspiratory load breathing (ILB). This study was approved by the institutional review board of Osaka City University Graduate School of Medicine (approval No. 2629), and registered with the University Hospital Medical Information Network-Clinical Trial Registry (study ID: UMIN 000011736). This study also conformed to the principles of the Declaration of Helsinki, and written informed consent was obtained from all of the subjects prior to the experiment.

The study design was a randomized, unblinded crossover study. The subjects were required to attend the laboratory on three separate days for three trials at different water depths, the umbilical level (UL), the 4th rib level (RL), and the clavicular level (CL) trials, in a random order, with at least 3 days separating each trial. In all sessions, a depth-variable water bath (AQUAEXMILL OCU1, Sanplatec, Osaka, Japan) was used, and the water temperature was maintained at $32 \pm 1.0$ (SD) ${ }^{\circ} \mathrm{C}$, the 'insensible temperature', to minimize the stress on the body 23,24$)$.

At the beginning of each session, subjects sat immersed in the water bath with the depth at the umbilical level for 5 min, and then the respiratory function and respiratory muscle strength were evaluated as baseline measurements. Next, subjects sat immersed at one of 3 different water levels (UL, RL, or CL). After an additional $5 \mathrm{~min}$, the measurements were repeated for the purpose of evaluating the effects of water immersion at the different depths on the respiratory function and respiratory muscle strength. Then, the subjects performed 15-min ILB in the sitting position, followed by the continuous evaluation of respiratory muscle strength immediately, and $5 \mathrm{~min}$, and $10 \mathrm{~min}$ after they had completed ILB immersed in water at the umbilical level in the sitting position. The water levels were adjusted by changing the height of the chair. The respiratory function and respiratory muscle strength after ILB were compared with those at baseline.

In the ILB, the subjects conducted 15 min breathing at a respiratory rate of 15 breaths per min, synchronized with a metronome, during which the inspiratory muscle load was adjusted to $30 \%$ of the maximum inspiratory pressure (PImax) at baseline using an inspiratory loading device (Threshold IMT, PHILIPS, USA). The load of 30\% of PImax during ILB was adopted, because it is commonly used as the load in the settings of respiratory muscle training for healthy subjects ${ }^{25)}$. The subjects were asked to take normal breaths by maintaining their tidal volumes (TVs) as in usual respiration at rest, not deep breaths, during the ILB.

Tidal volume (TV), VC, inspiratory capacity (IC), inspiratory reserve volume (IRV), and expiratory reserve volume (ERV) were measured as indices of respiratory function using a spirometer (AS-507, Minato, Osaka, Japan). PImax and maximum expiratory pressure (PEmax) in the oral cavity were also evaluated using a sthenometer attached to the spirometer (AAM337, Minato, Osaka, Japan) according to the method of Black and Hyatt ${ }^{26}$ and used as surrogate indices of inspiratory and expiratory muscle strength, respectively. Chest circumference (CC) was measured with a measuring tape at the xiphoid process level.

The rate of change of each parameter of respiratory function and respiratory muscle strength from baseline was calculated using the following equation:

rate of change $(\%)=[($ a measured value $)-($ baseline value $)] /($ baseline value $) \times 100$ 
Weight and height were measured before the first experiment. Body mass index (BMI in $\mathrm{kg} / \mathrm{m}^{2}$ ) was calculated as body weight $(\mathrm{kg})$ divided by height $(\mathrm{m})$ squared.

All statistical analyses were performed using Stat View statistical software package (Ver5.0, SAS, Cary, NC, USA). Data were expressed as the mean \pm standard deviation (SD) unless otherwise indicated. One-way analysis of variance (ANOVA) with repeated measurements and subsequent multiple pairwise comparisons (Scheffe method) was performed to evaluate the effects of water immersion at different water depths on the rate of change in the respiratory function and respiratory muscle strength from baseline. The effects of water depth and ILB on change and the rate of change in the respiratory function and respiratory muscle strength were examined using two-way (trial $\times$ time) ANOVA with repeated measurements. In the case of a significant time or trial effect, post-hoc multiple pairwise comparisons (Dunnett method) were performed. Statistical significance was accepted for values of $\mathrm{p}<0.05$.

\section{RESULTS}

Eight applicants, aged $21.3 \pm 0.5$ years, who met the inclusion criteria were enrolled in the present study. Their mean values of height, weight, and BMI were $1.73 \pm 0.1 \mathrm{~m}, 64.4 \pm 7.5 \mathrm{~kg}$, and $21.5 \pm 1.5 \mathrm{~kg} / \mathrm{m}^{2}$, respectively.

Changes in the parameters of respiratory function and respiratory muscle strength following water immersion in each trial are shown in Table 1. There were no significant changes in any parameter due to water immersion in each trial. When we compared the rates of change in each parameter among the three trials, as shown in Table 2, the decreases in VC (UL: $0.8 \pm$ 1.3, RL: $-1.7 \pm 1.2$, CL: $-9.7 \pm 1.0 \%, p=0.01$ for CL vs UL, $p=0.03$ for CL vs RL), ERV (UL: $1.2 \pm 1.6$, RL: $-17.1 \pm 6.1$, $\mathrm{CL}:-46.3 \pm 8.1 \%, \mathrm{p}=0.01$ for CL vs UL, $\mathrm{p}=0.02$ for CL vs RL), and CC (UL: $-0.1 \pm 0.1, \mathrm{RL}:-0.2 \pm 0.7, \mathrm{CL}:-1.1 \pm 0.1 \%$, $\mathrm{p}=0.04$ for CL vs UL, $\mathrm{p}=0.04$ for CL vs RL) from baseline were significantly greater in the CL trial than in the RL and the UL trials. The increase in IC was also significantly greater in the CL trial than that in the UL trial (UL: $-1.7 \pm 0.8, \mathrm{RL}$ : $10.7 \pm 4.1, \mathrm{CL}: 14.1 \pm 5.2 \%, \mathrm{p}=0.02$ for CL vs UL, $\mathrm{p}=0.12$ for CL vs RL). The rates of changes in the other parameters of respiratory function and muscle strength did not show significant differences among the trials.

Table 1. The effect of water immersion on respiratory function and respiratory muscle strength

\begin{tabular}{|c|c|c|c|c|c|c|}
\hline & \multicolumn{2}{|c|}{ UL } & \multicolumn{2}{|c|}{ RL } & \multicolumn{2}{|c|}{ CL } \\
\hline & Baseline & After immersion & Baseline & After immersion & Baseline & After immersion \\
\hline $\mathrm{VC}(\mathrm{L})$ & $4.1 \pm 0.7$ & $4.1 \pm 0.6$ & $4.0 \pm 0.5$ & $3.9 \pm 0.5$ & $4.0 \pm 0.5$ & $3.6 \pm 0.5$ \\
\hline TV (L) & $0.7 \pm 0.2$ & $0.7 \pm 0.2$ & $0.7 \pm 0.4$ & $0.7 \pm 0.4$ & $0.7 \pm 0.3$ & $0.8 \pm 0.3$ \\
\hline IC (L) & $2.4 \pm 0.6$ & $2.4 \pm 0.6$ & $2.3 \pm 0.5$ & $2.5 \pm 0.4$ & $2.5 \pm 0.6$ & $2.9 \pm 0.8$ \\
\hline ERV (L) & $1.6 \pm 0.4$ & $1.6 \pm 0.4$ & $1.7 \pm 0.5$ & $1.4 \pm 0.5$ & $1.5 \pm 0.4$ & $0.8 \pm 0.5$ \\
\hline IRV (L) & $1.7 \pm 0.6$ & $1.7 \pm 0.6$ & $1.7 \pm 0.4$ & $1.9 \pm 0.3$ & $1.8 \pm 0.4$ & $2.1 \pm 0.7$ \\
\hline $\mathrm{CC}(\mathrm{cm})$ & $76.8 \pm 5.1$ & $76.7 \pm 5.1$ & $76.1 \pm 5.2$ & $75.9 \pm 5.1$ & $76.8 \pm 5.2$ & $75.9 \pm 5.1$ \\
\hline $\operatorname{PEmax}\left(\mathrm{cmH}_{2} \mathrm{O}\right)$ & $104.4 \pm 22.8$ & $106.5 \pm 33.1$ & $101.5 \pm 20.8$ & $100.2 \pm 26.1$ & $105.3 \pm 25.8$ & $98.7 \pm 24.9$ \\
\hline $\operatorname{PImax}\left(\mathrm{cmH}_{2} \mathrm{O}\right)$ & $96.5 \pm 24.3$ & $92.4 \pm 19.9$ & $92.1 \pm 27.8$ & $89.6 \pm 27.5$ & $97.3 \pm 23.6$ & $90.1 \pm 24.1$ \\
\hline
\end{tabular}

Values are means $\pm \mathrm{SD}$.

UL: umbilicus; RL: 4th-rib; CL: clavicle; VC: vital capacity; TV: tidal volume; IC: inspiratory capacity; ERV: expiratory reserve volume; IRV: inspiratory reserve volume; CC: chest circumference; PEmax: maximal expiratory pressure; PImax: maximal inspiratory pressure

Table 2. The effect of water immersion at different water depths on the rate of change in respiratory function and respiratory muscle strength

\begin{tabular}{cccc}
\hline Rate of change (\%) & $\mathrm{UL}$ & $\mathrm{RL}$ & $\mathrm{CL}$ \\
\hline VC & $0.8 \pm 1.3$ & $-1.7 \pm 1.2$ & $-9.7 \pm 1.0^{*}$ § \\
TV & $-0.1 \pm 2.6$ & $5.4 \pm 6.5$ & $8.4 \pm 6.7$ \\
IC & $-1.7 \pm 0.8$ & $10.7 \pm 4.1$ & $14.1 \pm 5.2^{*}$ \\
ERV & $1.2 \pm 1.6$ & $-17.1 \pm 6.1$ & $-46.3 \pm 8.1^{*}$ \\
IRV & $-2.2 \pm 2.0$ & $14.4 \pm 5.6$ & $17.2 \pm 8.0$ \\
CC & $-0.1 \pm 0.1$ & $-0.2 \pm 0.7$ & $-1.1 \pm 0.1^{* \S}$ \\
PEmax & $2.1 \pm 3.6$ & $-1.2 \pm 3.1$ & $-6.3 \pm 2.3$ \\
PImax & $-4.3 \pm 2.4$ & $-2.7 \pm 3.5$ & $-7.3 \pm 2.4$ \\
\hline
\end{tabular}

Values are means \pm SEM. * $p<0.05$, vs. UL. $\$ p<0.05$, vs. RL.

Abbreviations are as Table 1 . 
Changes in respiratory muscle strength following ILB in each trial are shown in Table 3. There were no significant differences in these parameters among three trials. Regarding the rate of change in respiratory muscle strength following ILB, compared to the baseline, PImax was reduced immediately after ILB in the CL trial, and the reduction was significantly greater than in the RL and the UL trials (UL: $-7.0 \pm 1.5 \%, \mathrm{RL}:-6.7 \pm 4.8 \%, \mathrm{CL}:-14.1 \pm 4.1 \%, \mathrm{p}=0.04$ for CL vs UL, $\mathrm{p}$ $=0.03$ for CL vs RL). On the other hand, ILB did not affect PImax in the RL and the UL trials. PImax in the CL trial had recovered at 5 min after ILB. PEmax was not affected by ILB in any of the trials, and there was no difference in the rate of change in PEmax among the three trials.

\section{DISCUSSION}

In the present study, the decreases in VC and ERV during water immersion were significantly greater in the CL trial compared to those in the other trials. Agostoni et al. reported that $\mathrm{VC}$ and forced expiratory volume in $1 \mathrm{~s}$ during water immersion reduced in proportion to the depth of the water, and that the reduction became significant when the depth was at the cervical level ${ }^{16)}$. Dahlback and Buono et al. also reported that $\mathrm{VC}$ was significantly decreased by water immersion at the clavicle level ${ }^{27}, 28$ ). Our results corroborate the findings of these previous studies. Kurabayashi et al. reported that CC was reduced by $0.5 \mathrm{~cm}$ with water immersion at cervical level depth, compared to that before submersion ${ }^{29}$. In the present study, the reduction in CC was significantly greater in the CL trial than in the other trials, and this is also consistent with the results of Kurabayashi et al. Therefore, it is likely that the chest wall is compressed by the hydrostatic pressure of water immersion to the clavicular level or deeper. Speculation has emerged that the abdominal wall as well as the chest wall is compressed by hydrostatic pressure during water immersion resulting in cranial shift of the diaphragm, which would reduce the compliance of the chest cavity, or VC. A cranial shift in the diaphragm and reduced compliance of the chest cavity would also minimize the alveolar size at the end-expiratory phase, which may decrease ERV, and, in contrast, increase IC.

In the present study, neither PImax nor PEmax were affected by water immersion, regardless of the depth of the water. In regard to PImax, our results were consistent with the findings of Schoenhofer et al. ${ }^{30}$ ) who reported that PImax was decreased by water immersion to the clavicular level compared to the baseline before submersion, but that the decrease was not statistically significant. It is generally recommended that the measurement of PImax is performed at the maximum expiratory phase, based on the theory of the length-tension relationship ${ }^{31)}$. In short, the maximum expiratory phase is determined by the balance between expiratory muscle contraction and the opposing elastic dilatation pressure of the lung and thorax. In this phase, the inspiratory muscles and the diaphragm are extended to the utmost and demonstrate maximal tensile strength to generate maximal inspiratory pressure with the support of the elastic dilatation pressure of the lung and thorax. Water immersion could assist the subjects to easily retain maximum expiratory phase, and it may be the reason why PImax was not impaired by water immersion in the present study. Regarding PEmax, our results support the findings of de Andrade et al. ${ }^{19)}$ who reported that PEmax during water immersion did not differ regardless of the depth of the immersion. Primarily, submersion accompanied by decreases in $\mathrm{VC}$ and $\mathrm{CC}$ may be unfavorable conditions for measuring PEmax from the perspective of the length-tension relationship cited above. However, it is possible that hydrostatic pressure against the entire thorax in the CL trial may have assisted expiration resulting in minimal influence of immersion on PEmax.

To the best of our knowledge, no previous report has investigated the influence of water depth during submerged forced respiration on respiratory muscle fatigue. In the present study, the decrease in PImax immediately after ILB was significantly greater in the CL trial than that observed in the other trials. In the CL trial, it is possible that hydrostatic pressure against the entire thorax may have added an excessive load on the inspiratory muscle besides the original load of $30 \%$ of PImax during ILB. In addition, it is possible that an extra inspiratory load was elicited by reduced alveolar compliance following increased venous return under the influence of hydrostatic pressure on the lower extremities. This may be why the greatest decrease in PImax following ILB was found in the CL trial; it reflected more severe inspiratory muscle fatigue compared to the other trials.

Table 3. The effect of inspiratory load breathing at different water levels on respiratory muscle strength

\begin{tabular}{lcccc}
\hline & Baseline & 0 min after ILB & 5 min after ILB & 10 min after ILB \\
\hline PImax $\left(\mathrm{cmH}_{2} \mathrm{O}\right)$ & & & & \\
UL & $96.5 \pm 24.3$ & $89.7 \pm 20.9$ & $98.6 \pm 23.4$ & $99.4 \pm 22.8$ \\
RL & $92.1 \pm 27.8$ & $88.4 \pm 25.6$ & $94.2 \pm 24.5$ & $100.2 \pm 22.3$ \\
CL & $97.3 \pm 23.6$ & $84.4 \pm 23.2$ & $99.9 \pm 21.4$ & $100.5 \pm 25.4$ \\
PEmax $\left(\mathrm{cmH}_{2} \mathrm{O}\right)$ & & & & \\
UL & $104.4 \pm 22.8$ & $114.4 \pm 28.3$ & $102.7 \pm 23.5$ & $109.0 \pm 23.3$ \\
RL & $101.5 \pm 20.8$ & $94.3 \pm 23.1$ & $103.1 \pm 24.7$ & $99.8 \pm 25.7$ \\
$\mathrm{CL}$ & $105.3 \pm 25.8$ & $102.2 \pm 21.1$ & $103.8 \pm 20.0$ & $105.7 \pm 16.0$ \\
\hline
\end{tabular}

Values are means $\pm \mathrm{SD}$.

Abbreviations are as Table 1 . 
On the other hand, although it is considered that even in the RL trial, hydrostatic pressure against the lower part of thorax affected the expansion of the chest cavity, at least in part, there was no significant decrease in PImax following ILB in the RL trial, as well as in the UL trial. de Andrade et al. showed that neither water immersion to the depth of iliac crest nor the xiphoid process level reduced VC compared to that measured on dry land ${ }^{19)}$. Their findings suggest that immersion to the depth of the xiphoid process level or shallower does not yield enough hydrostatic pressure on the chest wall or venous return to the mediastinal space to impair the expansion of the chest cavity. Therefore, immersion to UL or RL in our study was unlikely to have additionally loaded the inspiratory muscles.

In the present study, the decrease in PImax immediately after ILB in the CL trial had completely recovered at 5 min after ILB. Our results support the findings of Suzuki et al. who reported that PImax was transiently decreased immediately after resistance load respiration training, but the decrease was no longer observed 5 min after the cessation of the training ${ }^{32}$. Approximately $60 \%$ of the muscle contained in the diaphragm is comprised of red muscle fibers ${ }^{33)}$, which are characterized by fatigue resistance and endurance strength. This may be a reason why fatigue of the inspiratory muscle induced by ILB was quickly recovered in our CL trial. In contrast to PImax, PEmax showed no change from baseline following ILB in any trial. In the present study, the expiratory muscles were not loaded in the expiratory phase during ILB. Furthermore, hydrostatic pressure against the chest wall could possibly have assisted expiratory muscles to contract. Therefore, our immersed ILB may have resulted in no remarkable fatigue of the expiratory muscles.

The results of this study suggest that the deeper the immersion depth, the greater the fatigue of the inspiratory muscles. Generally, training-associated factors which cause muscular fatigue, such as metabolic stress or local hypoxia, are necessary for eliciting muscular hypertrophy and strengthening ${ }^{34)}$. Therefore, the results of this study have important implications for exercise in water for patients with chronic respiratory diseases, in which the strengthening of respiratory muscles is widely accepted as a therapeutic strategy. Regardless of the presence of a chronic disease, from a health promotion perspective, our results will be useful for determining the depth of water for aquatic exercise. However, it is not clear whether training producing greater inspiratory muscle fatigue results in greater muscle strength. It also has to be determined whether the results of our study of healthy young adults can wholly be applied to patients with chronic respiratory diseases whose respiratory muscles are already fatigued, even at rest. In addition, the water resistance during aquatic exercise varies according to the kinetic rate, i.e., a lower kinetic rate correlates with a smaller water resistance in aquatic exercise. It is possible that respiration in water at low frequency reduces the load against the chest wall in aquatic respiration exercise. Therefore, it is necessary to develop effective aquatic exercise protocols for strengthening respiratory muscles.

The present study had some limitations. First, the values of PImax and PEmax had high variation among individuals. Therefore, the small number of subjects may not have been enough to verify the influence of ILB on respiratory muscle fatigue. Furthermore, our subjects performed ILB with a prescribed inspiratory load and respiratory rate. However, subjects were only asked to maintain their TVs with normal respiration at rest. Although we found no significant difference in TVs during water immersion among the trials, it is not certain whether the subjects could keep TVs during ILB constant across the trials. Therefore, there is a possibility that differences in TVs influenced the magnitude of inspiratory muscle fatigue.

In summary, forced respiration during the deepest level of water immersion caused the greatest inspiratory muscle fatigue in healthy young men. Further studies are needed to develop an exercise regimen that can be utilized in the field of sports or clinical settings that makes the most of the characteristics of submersion and aquatic exercise.

\section{REFERENCES}

1) Sugiura H, Ohta K, Ninatani S, et al.: Rekationship between resoiratory muscle strength and exercise tolernce. J Phys Ther Sci, 2009, 21: 393-397. [CrossRef]

2) Smith K, Cook D, Guyatt GH, et al.: Respiratory muscle training in chronic airflow limitation: a meta-analysis. Am Rev Respir Dis, 1992, 145: 533-539. [Medline] [CrossRef]

3) McCool FD: Global physiology and pathophysiology of cough: ACCP evidence-based clinical practice guidelines. Chest, 2006, 129: 48S-53S. [Medline] [CrossRef]

4) Kulnik ST, Rafferty GF, Birring SS, et al.: A pilot study of respiratory muscle training to improve cough effectiveness and reduce the incidence of pneumonia in acute stroke: study protocol for a randomized controlled trial. Trials, 2014, 15: 123. [Medline] [CrossRef]

5) Janssens JP, Krause KH: Pneumonia in the very old. Lancet Infect Dis, 2004, 4: 112-124. [Medline] [CrossRef]

6) Jung J, Lee J, Chung E, et al.: The effect of obstacle training in water on static balance of chronic stroke patients. J Phys Ther Sci, 2014, 26: 437-440. [Medline] [CrossRef]

7) Wilcock IM, Cronin JB, Hing WA: Physiological response to water immersion: a method for sport recovery? Sports Med, 2006, 36: 747-765. [Medline] [CrossRef]

8) Sheldahl LM: Special ergometric techniques and weight reduction. Med Sci Sports Exerc, 1986, 18: 25-30. [Medline] 
[CrossRef]

9) Chi D, Back Y, Park G, et al.: The effect of aquatic exercise on peak torque and stability of knee joints of elderly women. J Phys Ther Sci, 2011, 23: 871-873. [CrossRef]

10) Irandoust $\mathrm{K}$, Taheri M: The effects of aquatic exercise on body composition and nonspecific low back pain in elderly males. J Phys Ther Sci, 2015, 27: 433-435. [Medline] [CrossRef]

11) Han G, Cho M, Nam G, et al.: The effects on muscle strength and visual analog scale pain of aquatic therapy for individuals with low back pain. J Phys Ther Sci, 2011, 23: 57-60. [CrossRef]

12) Lee DG, Jeong SK, Kim YD: Effects of underwater treadmill walking training on the peak torque of the knee in hemiplegic patients. J Phys Ther Sci, 2015, 27: 2871-2873. [Medline] [CrossRef]

13) Bondi KR, Young JM, Bennett RM, et al.: Closing volumes in man immersed to the neck in water. J Appl Physiol, 1976, 40: 736-740. [Medline]

14) Craig AB Jr, Dvorak M: Expiratory reserve volume and vital capacity of the lungs during immersion in water. J Appl Physiol, 1975, 38: 5-9. [Medline]

15) Craig AB Jr, Ware DE: Effect of immersion in water on vital capacity and residual volume of the lungs. J Appl Physiol, 1967, 23: 423-425. [Medline]

16) Agostoni E, Gurtner G, Torri G, et al.: Respiratory mechanics during submersion and negative-pressure breathing. J Appl Physiol, 1966, 21: 251-258. [Medline]

17) Leith DE, Mead J: Mechanisms determining residual volume of the lungs in normal subjects. J Appl Physiol, 1967, 23: 221-227. [Medline]

18) Prefaut C, Lupi-h E, Anthonisen NR: Human lung mechanics during water immersion. J Appl Physiol, 1976, 40: 320-323. [Medline]

19) de Andrade AD, Júnior JC, Lins de Barros Melo TL, et al.: Influence of different levels of immersion in water on the pulmonary function and respiratory muscle pressure in healthy individuals: observational study. Physiother Res Int, 2014, 19: 140-146. [Medline] [CrossRef]

20) Ide MR, Belini MA, Caromano FA: Effects of an aquatic versus non-aquatic respiratory exercise program on the respiratory muscle strength in healthy aged persons. Clinics (Sao Paulo), 2005, 60: 151-158. [Medline] [CrossRef]

21) McNamara RJ, McKeough ZJ, McKenzie DK, et al.: Water-based exercise in COPD with physical comorbidities: a randomised controlled trial. Eur Respir J, 2013, 41: 1284-1291. [Medline] [CrossRef]

22) Jung J, Chung E, Kim K, et al.: The effects of aquatic exercise on pulmonary function in patients with spinal cord injury. J Phys Ther Sci, 2014, 26: 707-709. [Medline] [CrossRef]

23) Craig AB, Dvorak M: Comparison of exercise in air and in water of different temperatures. Med Sci Sports Exerc, 1969, 1: 124-130. [CrossRef]

24) Evans BW, Cureton KJ, Purvis JW: Metabolic and circulatory responses to walking and jogging in water. Res Q, 1978, 49: 442-449. [Medline]

25) Suzuki S, Yoshiike Y, Suzuki M, et al.: Inspiratory muscle training and respiratory sensation during treadmill exercise. Chest, 1993, 104: 197-202. [Medline] [CrossRef]

26) Black LF, Hyatt RE: Maximal respiratory pressures: normal values and relationship to age and sex. Am Rev Respir Dis, 1969, 99: 696-702. [Medline]

27) Dahlbäck GO, Jönsson E, Linér MH: Influence of hydrostatic compression of the chest and intrathoracic blood pooling on static lung mechanics during head-out immersion. Undersea Biomed Res, 1978, 5: 71-85. [Medline]

28) Buono MJ: Effect of central vascular engorgement and immersion on various lung volumes. J Appl Physiol, 1983, 54: 1094-1096. [Medline]

29) Kurabayashi HT, Kubota K, Tamura J: Analysis of the circumferences of chest, abdomen, thigh and calf during headout water immersion. Climatol Phys Med, 2001, 64: 199-202.

30) Schoenhofer B, Koehler D, Polkey MI: Influence of immersion in water on muscle function and breathing pattern in patients with severe diaphragm weakness. Chest, 2004, 125: 2069-2074. [Medline] [CrossRef]

31) Agostoni E, Mead J: Statics of the respiratory system. In: Handbook of Physiology; Washington DC: American Physiological Society, 1964, pp 387-409.

32) Suzuki S, Suzuki J, Okubo T: Expiratory muscle fatigue in normal subjects. J Appl Physiol 1985, 1991, 70: $2632-2639$. [Medline] 
33) Keens TG, Bryan AC, Levison H, et al.: Developmental pattern of muscle fiber types in human ventilatory muscles. $\mathrm{J}$ Appl Physiol, 1978, 44: 909-913. [Medline]

34) Rooney KJ, Herbert RD, Balnave RJ: Fatigue contributes to the strength training stimulus. Med Sci Sports Exerc, 1994, 26: 1160-1164. [Medline] 